\title{
RESEARCH
}

\section{THE RELATIONSHIP OF PRESBYCUSIS WITH COGNITIVE FUNCTIONS}

Turkish Journal of Geriatrics DOI: 10.31086/tjgeri.2020.140 2020; 23(1): 75-81

- Şükran YURTOĞULLARI ${ }^{1}$ n Elif Gülin KOÇAN ${ }^{2}$ (D)

- Gönül VURAL ${ }^{3}$ (D) n Şadiye GÜMÜŞYAYLA ${ }^{3}$ D - Mehmet All BABADEMEZ ${ }^{4}$ (D) - Kazım BOZDEMIR ${ }^{4}$ (D)

CORRESPONDANCE

Şükran YURTOĞULLARI

Ankara Atatürk Training and Research Hospital Department of Neurology, Neurology, Ankara, TURKEY

Phone: +905332508298

e-mail: sukranyurtogullari@hotmail.com

Received: 01/07/2019

Accepted: 27/12/2019

1 Ankara Atatürk Training and Research Hospital Department of Neurology, Neurology, Ankara, TURKEY.

${ }^{2}$ Ankara Atatürk Training and Research Hospital Department of Ear-Nose-Throat, Ear-Nose-Throat, Ankara, TURKEY.

${ }^{3}$ Ankara Yildirim Beyazit University, Medical Faculty, Neurology, Ankara, TURKEY.

${ }^{4}$ Ankara Yildirim Beyazit University, Medical Faculty, Ear-Nose-Throat, Ankara, TURKEY.

\section{A}

Introduction: Presbycusis, age-related hearing loss, is one of the most common diseases in geriatric patients. The present study aims to achieve early diagnosis of presbycusis, prevent cognitive disorders, avoid social isolation, and provide guidance for the treatment.

Materials and Method: Presbycusis was diagnosed by routine biochemical, hormone, and audiological tests in patients aged $\geq 50$ years with hearing loss who were admitted to the ear-nose-throat outpatient clinic. Cognitive impairment was examined by a neurologist; all patients received the Mini-Mental State Examination and Clock Drawing Test. Patients with dementia caused by metabolic and toxic disorders, and patients with depression who scored $>10$ on Beck's depression scale were excluded from the study.

Results: This prospective study was conducted between February 2016 and June 2017. A total of 73 patients were included in the study; the mean \pm SD age was $71.44 \pm 8.12$ (min-max: $48-88)$ years; $42.5 \%(n=31)$ were men and $57.5 \%(n=$ 42) women. Following age correction, the Mini-Mental State Examination score of patients with hearing loss was lower than those without (Corrected $Z=2.229 ; \mathrm{p}=$ 0.026). The Clock Drawing Test score was lower in patients with hearing loss than those without (Corrected $Z=3.302 ; \mathrm{p}<0.001$ ).

Conclusion: The present study revealed that presbycusis is neglected but significant cause of dementia and leads to its rapid development. Close and regular monitoring of hearing loss in geriatric patients and enhancement of social awareness on this issue are important factors for preventing dementia.

Keywords: Presbycusis; Cognitive Dysfunction; Dementia. 


\section{INTRODUCTION}

According to the United Nations (UN) data anticipates that by 2020 world's population of individuals over 65 years of age will be 698 million $(9.3 \%$ of the whole population) (1). In Turkey, however, the population of individuals over 65 years of age was $7.3 \%$ in 2011 and this ratio has been speculated to reach up to $17.6 \%$ in 2050 (2). Worldwide approximately 328 million adults suffer from hearing impairment, approximately $1 / 3$ of the population over 65 years of age have been affected by hearing loss (3). According to the data of $\mathrm{WHO}$, when the total of healthy years missed due to disability is evaluated, presbycusis ranks third among the causes leading to this loss (4).

Hearing problems are extremely common in elderly individuals, with a general prevalence of $23-48 \%$ over 65 years of age. The most common cause of hearing loss is presbycusis, which is progressive and bilateral high-frequency hearing loss. It physiologically occurs during the third decade and at high frequencies (5). It begins to influence the frequencies involving speech spectrum by the fifth decade. In most cases, people around the individuals recognize the hearing loss before the individual himself/herself. Difficulties in perceiving fast speech and having difficulties in recognition and differentiation of words in noisy media are generally described in the history. Therefore, admission complaints are as "hearing but not being able to understand the speech". Presbycusis is an exclusion diagnosis. It should be excluded through evaluating etiologies that may lead to hearing loss in elderly (6). Environmental factors (exposure to noise, use of ototoxic medications, alcohol intake, chronic diseases like diabetes, trauma, otological diseases etc.) and genetic factors are effective in development of presbycusis (7-10).

Presbycusis has been shown that influence life quality negatively by leading to situations such as limitation in social activities, loneliness, isolation, communicative disorders and dissatisfaction with family (11-13). There is also an association between presbycusis and dementia. Risk of developing dementia is increased two-fold in individuals with slight hearing loss, three-fold in individuals with moderate hearing loss and five-fold in those with severe hearing loss, compared to individuals with normal hearing functions (14). Hearing loss also leads to decrement in cognitive functional capacity of individuals (15).

It is clear that screening of hearing disorders are not sufficiently performed; it is performed in primary health care services routinely but to some extent. Patients unfortunately, cannot think that they should ask for help for such an issue. There are many screening tests for hearing; whispered voice test is the simplest in which a physician stands outside the visual field and $30 \mathrm{~cm}$ away from the relevant ear of the patient, and the patient is supposed to repeat at least $50 \%$ of the words whispered. While a screening test, the gold standard is audiometric measurement; if patients cannot hear voices at 1000 or $2000 \mathrm{~Hz}$ frequency with one or both ears, patients must be then referred to an ENT specialist. Hearing function is recommended to be checked up annually. By this means, early detection of presbycusis becomes possible and s/ he can be closely followed-up for risk of potential dementia and preventive measures can be taken.

\section{MATERIAL AND METHOD}

Our study was conducted in a prospective manner between the dates of February 2016 to June 2017 in accordance with the principles determined in the Declaration of Helsinki. The study was approved by the Ethics Committee of Ankara Training and Research Hospital (2016/4/13-129). Patients over 50 years of age with suspected hearing loss who admitted to ENT outpatient clinic were examined by an ear-nose-throat specialist for presbycusis through exclusion of other potential causes. Routine biochemical and hormone tests and audiological tests were performed. The patients were assessed with minimental test (MMT) 
and clock drawing tests by a neurologist who was unaware of the audiological tests. Accompanying diseases, organic and metabolic causes which may lead to dementia were excluded, Beck's depression scale was applied to the patients for exclusion of depression and those received scores over 10 were excluded from the study.

\section{Statistical Analyses}

Distribution of age and MMT score in the study was examined by using Shapiro-Wilk test. Age was summarized as mean \pm standard deviation $($ mean $\pm s), M M T$ and clock drawing scores were summarized as median (min-max). Categorical variables such as gender ere expressed as $n(\%)$.

Age, MMT and clock drawing test scores by hearing loss were compared by using Mann-Whitney $U$ test. While age varies among groups and there was a statistically and clinically significant difference between MMT and clock drawing test scores, MMT and clock drawing scores by hearing loss were re-compared after corrected according to age. Changes in scores after a 6-month period was calculated as (Initial score - 6th month score)/ (initial score) for MMT, because there were 0s in the initial values, as (initial score - 6th month score) for clock drawing test. Changes in the scores also were compared after age correction. While the data did not meet ANCOVA assumptions, age correction was performed with nonparametric ANCOVA and results of this test were provided. Three patients were excluded from the analysis because of advanced dementia. While ages of housewives and retired individuals were similar, their MMT and clock drawing tests were compared without any correction. A p-value of less than 0.05 was considered to show statistical significance.

Table 1. Demographical features.

\begin{tabular}{|c|c|c|}
\hline & $\begin{array}{r}\text { Mean } \pm S \\
n\end{array}$ & $\begin{array}{r}\text { Min-Max } \\
\% \\
\end{array}$ \\
\hline Age & $71.44 \pm 8.12$ & $48-88$ \\
\hline \multicolumn{3}{|l|}{ Gender } \\
\hline Male & 31 & 42.5 \\
\hline Female & 42 & 57.5 \\
\hline \multicolumn{3}{|l|}{ Educational Level } \\
\hline Illiterate & 1 & 1.4 \\
\hline Primary school & 24 & 32.9 \\
\hline Secondary school & 5 & 6.8 \\
\hline High school & 23 & 31.5 \\
\hline Graduate school & 20 & 27.4 \\
\hline \multicolumn{3}{|c|}{ Status of Employment } \\
\hline Housewife & 24 & 32.9 \\
\hline Retired & 46 & 63.0 \\
\hline Employed & 3 & 4.1 \\
\hline
\end{tabular}


Table 2. Features Regarding Hearing Loss and Dementia.

\begin{tabular}{|c|c|c|}
\hline & Baseline & $6^{\text {th }}$ Month \\
\hline MMT Score [median (range)] & $28(17-30)$ & $27(16-30)$ \\
\hline \multicolumn{3}{|l|}{ MMT group [n (\%)] } \\
\hline Moderate & $1(1.4)$ & $3(41)$ \\
\hline Slight & $13(17.8)$ & $20(27.4)$ \\
\hline Normal & $59(80.8)$ & $50(68.5)$ \\
\hline Clock Drawing Test Score [median (range)] & $7(0-7)$ & $6(0-7)$ \\
\hline
\end{tabular}

IBM SPSS Statistics 21.0 (IBM Corp. Released 2012. IBM SPSS Statistics for Windows, Version 21.0. Armonk, NY: IBM Corp.) program was used for statistical analyses and calculations.

\section{RESULTS}

The study was conducted between the dates February 2016 to June 2017. 83 patients over 50 years of age were included in the study. Ten patients with severe dementia were excluded from the study.

Of the patients included in the study; 31 were male $(42.5 \%)$ and 42 were female (57.5\%). Mean age of the 73 patients was $71.44 \pm 8.12$ years (minmax:48-88) (Table 1). Of the patients; $32.9 \%(n=24)$ were primary school graduate and $31.5 \%(n=23)$ were high school graduate. It was determined that 46 patients $(63.0 \%)$ were retired and 3 patients (4.1\%) were employed. It was observed that 47 (64.4\%) of the patients had hearing loss, MMT results of 59 (80.8\%) were normal and Magnetic Resonance Imaging (MRI) results of 34 (46.6\%) were normal.

MMT and Clock Drawing test results were presented in Table 2 at baseline and 6th month results. The mean MMT score was 28 at baseline and 27 at the end of the 6th month. The Clock Drawing Test Score was 7 at the beginning and 6 at the end of the 6th month (Table 2).
Median age was 74 years (min-max:50-88) in patients with hearing loss and 69 years (min-max: 48-75) in patients without hearing loss. Ages of patients with hearing loss were observed to be higher $(Z=4.315 ; p<0.001)$.

Median initial MMT score was 26 (min-max: 17-30) in patients with hearing loss and 29 (minmax: 26-30) in patients without hearing loss (Table 3). With corrected according to age, MMT score of patients with hearing loss was determined to be lower compared to those without hearing loss (Corrected $Z=2.229 ; p=0.026$ ).

Median sixth month MMT score was 25 (minmax: 16-29) in patients with hearing loss and 29 (min-max: 26-30) in patients without hearing loss (Table 3). With corrected according to age, when sixth month MMT scores were compared, scores of patients with hearing loss were observed to be lower (Corrected $Z=3.980 ; p<0.001$ ).

Sixth month MMT score in patients with hearing loss was determined to be reduced by a median of $7.14 \%$ (min-max: $0.0 \%-15.0 \%$ ) compared to the initial score (Table 3 ). The median of this change in patients without hearing loss was $0 \%$ (min-max: $3.85 \%-7.14 \%$ ). When the percentage of change in MMT scores were compared between the two groups with corrected according to age, the difference between them was determined to be sig- 
Table 3. Comparison of results of MMT test and clock drawing test by hearing loss.

\begin{tabular}{|c|c|c|c|c|}
\hline & & Hearing Loss & & Corrected \\
\hline & No & Yes & $z ; p$ & $\mathrm{Z} ; \mathrm{p}$ \\
\hline Initial MMT & & & & \\
\hline Median (min-max) & $29(26-30)$ & $26(17-30)$ & $4.036 ;<0.001$ & $2.229 ; 0.026$ \\
\hline $6^{\text {th }}$ Month MMT & & & & \\
\hline Median (min-max) & $29(26-30)$ & $25(16-29)$ & $5.575 ;<0.001$ & $3.980 ;<0.001$ \\
\hline MMT difference (\% & & & & \\
\hline Median (min-max) & $0.00(-3.85-7.14)$ & $7.14(0.00-15.00)$ & $6.063 ;<0.001$ & $4.776 ;<0.001$ \\
\hline Initial Clock Drawi & & & & \\
\hline Median (min-max) & $7(6-7)$ & $6(0-7)$ & $4.348 ;<0.001$ & $1.891 ; 0.059$ \\
\hline $6^{\text {th }}$ Month clock dr & & & & \\
\hline Median (min-max) & $7(0-7)$ & $5(0-7)$ & $4.463 ;<0.001$ & $3.302 ; 0.001$ \\
\hline Clock drawing diff & & & & \\
\hline Median (min-max) & $0(0-7)$ & $0(-6-2)$ & $1.565 ; 0.118$ & $3.863 ;<0.001$ \\
\hline
\end{tabular}

*(initial score-6th month score)/(initial score)*100. ${ }^{* *}$ initial score-6th month score.

Table 4. Comparison of MMT and clock drawing test scores.

\begin{tabular}{|c|c|c|c|c|}
\hline & \multicolumn{2}{|r|}{ Hearing Loss } & \multicolumn{2}{|r|}{ Corrected } \\
\hline & No & Yes & $Z_{i} p$ & $\mathrm{Z} ; \mathrm{p}$ \\
\hline \multicolumn{5}{|l|}{ Initial MMT } \\
\hline Median (min-max) & $29(26-30)$ & $26(17-30)$ & $4.036 ;<0.001$ & $2.229 ; 0.026$ \\
\hline \multicolumn{5}{|l|}{$6^{\text {th }}$ Month MMT } \\
\hline Median (min-max) & $29(26-30)$ & 25 (16-29) & $5.575 ;<0.001$ & $3.980 ;<0.001$ \\
\hline \multicolumn{5}{|c|}{ MMT difference $(\%)^{\star}$} \\
\hline Median (min-max) & $0.00(-3.85-7.14)$ & $7.14(0.00-15.00)$ & $6.063 ;<0.001$ & $4.776 ;<0.001$ \\
\hline \multicolumn{5}{|c|}{ Initial Clock Drawing Test } \\
\hline Median (min-max) & $7(6-7)$ & $6(0-7)$ & $4.348 ;<0.001$ & $1.891 ; 0.059$ \\
\hline \multicolumn{5}{|c|}{$6^{\text {th }}$ Month clock drawing test } \\
\hline Median (min-max) & $7(0-7)$ & $5(0-7)$ & $4.463 ;<0.001$ & $3.302 ; 0.001$ \\
\hline \multicolumn{5}{|c|}{ Clock drawing difference $^{\star \star}$} \\
\hline Median (min-max) & $0(0-7)$ & $0(-6-2)$ & $1.565 ; 0.118$ & $3.863 ;<0.001$ \\
\hline
\end{tabular}

*(initial score-6th month score)/(initial score)*100. ${ }^{* *}$ initial score-6th month score. 
nificant (Corrected $Z=4.776 ; p<0.001$ ). MMT score in patients with hearing loss was determined to decrease more.

After corrected according to age, it was concluded that patients with and without hearing loss were similar in regard to the initial clock drawing test (Corrected $Z=1.891 ; p=0.059$ ). 6th month clock drawing score was lower in patients with hearing loss (corrected $Z=3.302 ; p<0.001$ ). When the change in clock drawing score was examined, it was determined that more reduction occurred in patients with hearing loss (Corrected $Z=3.863$; $\mathrm{p}<0.001$ ).

There were no differences between retired individuals and housewives I terms of age, MMT score, clock drawing score and changes in these scores at the 6th month compared to the beginning ( $p>0.05$, Table 4).

\section{DISCUSSION}

Individuals with hearing loss had a higher risk of impaired cognitive functions and presence of dementia (16-17). In our study, both initial and 6th

\section{REFERENCES}

1. Shrestha LB. Population aging in developing countries. Health Aff (Millwood). 2000 MayJun;19(3):204-12. (PMID: 10812800 ).

2. Ceritoğlu E, Eren $O$. The effects of demographic and social changes on household savings in Turkey. Central Bank Review Vol.14 (September 2014), pp. 15-33 [internet] Available from: https://www3.tcmb. gov.tr/cbr/ Accessed: 27.06.2019

3. Murray CJL, Lopez AD, Mathers CD, Stein C. The Global Burden of Disease 2000 Project: aims, methods and data sources. Geneva: World Health Organization; 2001. Global Programme on Evidence for Health Policy Discussion paper N. 36. [Internet] Available from: URL: http:/www.who.int/entity/en/ Accessed: 27.06.2019

4. Tucci D, Merson MH, Wilson BS. A summary of the literature on global hearing impairment: current status and priorities for action. Jan 2010, 31(1):31-41. month MMT scores and clock drawing scores were compared, in evaluations by the end of 6th month, particularly patients with presbycusis were determined to have a statistically significant reduction in both of two scores. Hearing loss over 60 years of age is more than $30 \%$ as is shown in previous study. Similarly, in our study, median age was 74 years (min-max:50-88) in patients with hearing loss and 69 years (min-max: 48-75) in patients without hearing loss. Ages of patients with hearing loss were observed to be higher $(Z=4.315 ; p<0.001)$. This can be a risk factor for dementia (18).

Hearing loss is independently associated with dementia. Larger studies are need to determine whether hearing loss is a marker for early-stage dementia or a modifiable risk factor for dementia. When the increment in elderly population worldwide and in our country is taken into consideration, it is extremely crucial to pay attention to this health issue, presbycusis, whose determination is extremely easy. Referral of patients with hearing impairment detected by taking this into consideration in primary health care services to relevant specialties is of vital importance in regard to public health by reducing risk of potential dementia.

\section{(PMID: 20050266).}

5. Davis, A., McMahon, C. M., Kathleen M. et al. Aging and hearing health: the life-course approach. The Gerontologist, 2016 April; 56: 256- 267. (PMID: 26994265).

6. Gates GA, Mills JH. Presbycusis. Lancet 2005 Sept 2430; 366(9491): 1111-20. (PMID: 16182900).

7. Huang Q, Tang J. Age-related hearing loss or presbycusis. Eur Arch Otorhinolaryngol 2010 Aug; 267(8): 1179-91. (PMID: 20464410).

8. Tremblay K, Ross B. Effects of age and age-related hearing loss on the brain. J Commun Disord 2007JulAug; 40(4): 305-12. (PMID: 17433356).

9. Ciorba A, Benatti A, Bianchini C, et al. High frequency hearing loss in the elderly: effect of age and noise exposure in an Italian group. J Laryngol Otol 2011 Aug; 125(8): 776-80. (PMID: 21729437) 
10. Bovo R, Ciorba A, Martini A. Environmental and genetic fac $\neg$ tors in age-related hearing impairment. Aging Clin Exp Res 2011 Feb; 23(1): 3-10. (PMID: 21499014).

11. Strauss S, Swanepoel DW, Becker $P$, et al. Noise and age-related hearing loss: a study of 40123 gold miners in South Africa. Int J Audiol. 2014 Mar;53 Suppl 2:S6675. (PMID: 24564695).

12. Humes LE, Dubno JR, Gordon-Salant $S$, et al. Central presbᄀycusis: a review and evaluation of the evidence. J Am Acad Audiol 2012; 23(8): 635-66. (PMID: 22967738).

13. Lotfi Y, Mehrkian S, Moossavi A, Faghih-Zadeh S. Quality of life improvement in hearing-impaired elderly people after wearing a hearing aid. Arch Iran Med 2009; 12(4): 365-70. (PMID: 19566353).

14. Lin FR, Metter EJ, O'Brien RJ, et al. Hearing loss and incident dementia. Arch Neurol 2011; 68(2): 214-20. (PMID: 21320988).
15. Arlinger S. Negative consequences of uncorrected hearing loss--a review. Int J Audiol 2003; 42(Suppl 2): 2S17-20. (PMID: 12918624).

16. Kiessling J, Pichora-Fuller MK, Gatehouse S, et al. Candidature for and delivery of audiological services: special needs of older people. Int J Audiol 2003; 42(Suppl 2): 2S92-101. (PMID: 12918635).

17. Popelka MM, Cruickshanks KJ, Wiley TL, et al. Low prevalence of hearing aid use among older adults with hearing loss: the Epidemiology of Hearing Loss Study. J Am Geriatr Soc 1998; 46(9): 1075-8. (PMID: 9736098).

18. Cacciatore F, Napoli C, Abete P, et al. Quality of life determinants and hearing function in an elderly population: Osservatorio Geriatrico Campano Study Group. Gerontology 1999 Nov-Dec;45(6):323-8. (PMID: 10559650). 